Article

\title{
A Diverse and Sustainable Biodiesel Supply Chain Optimisation Model Based on Properties Integration
}

\author{
Chun Hsion Lim ${ }^{1, *}$, Wei Xin Chua ${ }^{1}$, Yi Wen Pang ${ }^{1}$, Bing Shen How ${ }^{2}{ }^{-}$, Wendy Pei Qin Ng ${ }^{3}$, \\ Sin Yong Teng ${ }^{4}\left(\right.$, Wei Dong Leong ${ }^{5}$, Sue Lin Ngan ${ }^{6}$ and Hon Loong Lam ${ }^{5}$ \\ 1 Department of Chemical Engineering, University Tunku Abdul Rahman, Jalan Sungai Long, \\ Bandar Sungai Long, Cheras, Kajang 43000, Malaysia; elfchua97@1utar.my (W.X.C.); \\ evangelinepng@1utar.my (Y.W.P.) \\ 2 Research Centre for Sustainable Technologies, Faculty of Engineering, Computing and Science, \\ Swinburne University of Technology, Jalan Simpang Tiga, Kuching 93350, Malaysia; \\ bshow@swinburne.edu.my \\ 3 Department of Chemical Engineering, Curtin University Malaysia, CDT 250, Miri 98009, Malaysia; \\ wendyngpq@curtin.edu.my \\ 4 Institute of Process Engineering \& NETME Centre, Brno University of Technology, Technicka 2896/2, \\ 61669 Brno, Czech Republic; Sin.Yong.Teng@vut.cz \\ 5 Department of Chemical and Environmental Engineering, University of Nottingham Malaysia, \\ Semenyih 43500, Malaysia; ebxw11@nottingham.edu.my (W.D.L.); \\ honloong.lam@nottingham.edu.my (H.L.L.) \\ 6 UKM-Graduate School of Business, Universiti Kebangsaan Malaysia, Bangi 43600, Malaysia; \\ suelin.ngan@ukm.edu.my \\ * Correspondence: chlim@utar.edu.my; Tel.: +60-39086-0288
}

Received: 19 August 2020; Accepted: 25 September 2020; Published: 13 October 2020

check for updates

\begin{abstract}
Producing sustainable biodiesel from oil crops has been a great challenge, especially for oil crops plantations that involve various small and medium stakeholders. Differences in plantation activities and environments create a unique sustainability profile for each oil crop that may impose more sustainability issues such as deforestation problems in oil palm plantations. This paper embraced the unique sustainability index profile of each oil crop, and an investigation was performed to evaluate the feasibility of integrating multiple oil crops into the existing biodiesel refinery to improve its economic and sustainability performances. The selection of the process feed is proposed to be based on oil crop properties such as iodine value, peroxide value and saturated and unsaturated fatty acid contents. The sustainability profiles considered in the study include deforestation, oil yield, fertiliser impact, water impact and carbon footprint. Case studies demonstrated that a more balanced sustainability index profile could be achieved at a higher production cost_from USD $6.43 \mathrm{billion} \cdot \mathrm{y}^{-1}$ in a cost-saving-centric solution to USD $39.90 \mathrm{billion} \cdot \mathrm{y}^{-1}$ in a sustainability-improvement-centric solution. The study provided excellent insight into the impact on production cost to achieve sustainability which can help stakeholders to evaluate the feasibility of integrating multiple oil crops in the system.
\end{abstract}

Keywords: biodiesel supply chain optimisation; properties integration; sustainable biodiesel; sustainability optimisation

\section{Introduction}

Energy is unquestionably one of the most significant driving forces for developing and advancing a nation. With the increasing population and advancement of technology, energy consumption and demand are increasing rapidly. Alternative sources of energy are needed to achieve a better and sustainable system. Biodiesel is a cleaner-burning fuel consisting of alkyl esters produced 
from the transesterification of triglycerides (TGs) or esterification of free fatty acids (FFAs) with low-molecular-weight alcohols [1]. Biodiesel has been one of the desired alternative fuels to replace petrodiesel due to its similar properties and lower emission of pollutants [2]. The main sources for biodiesel production are edible and non-edible oil crops, such as palm oil, soybean, canola, rapeseed and microalgae [3-5]. The conversion of edible oil crops into biofuel has created many issues around the ideology of using food as an energy source. In addition, concerns were raised in regards to the sustainability of the oil crop plantation. For example, a report revealed that the palm oil industry causes deforestation, habitat loss, water and air pollutions and forest fire issues [6]. This raises concerns about the sustainability performance of biodiesel, although it is produced from renewable resources.

A variety of research has been conducted to improve the sustainability performance of biodiesel production. For example, an input-output model was proposed to improve the sustainability of oil palm plantations [7]. The biodiesel supply chain is simulated in a multi-objective model to analyse the impact of market risk attitudes towards sustainability performance [8]. A study on an animal-fat-based biodiesel supply chain network integrated with risk management and uncertainty consideration showed that the logistics cost was the second-highest expenditure next to installation cost [9]. The integration of wastewater sludge has shown great potential in biodiesel production based on a data-driven optimisation model with the inclusion of uncertainty analysis and fuzzy approach [10]. Biodiesel production derived from Jatropha Curcas is designed in a two-stage stochastic programming approach which shows that the integration of different kinds of biodiesels can result in a more comprehensive and green system [11]. A study shows that microalgae-based biodiesel is feasible; however, the conversion substantially depends on the lipidic characteristic of the feed [12]. Various studies show that waste cooking oil could be a promising source for biodiesel production for the more sustainable practice of utilising waste as an energy source [13-15]. A comparison between petrodiesel, palm biodiesel and opium poppy biodiesel shows that the latter biodiesel has better energetically sustainable performance in the engine [16].

From the literature, multiple alternative resources have been investigated to improve sustainability performance in biodiesel production. The majority of the researchers investigated the integration of alternative non-edible and renewable oil sources and compared the sustainability performance with the conventional approach. However, a recent study shows that different types of oil (e.g., palm oil, rapeseed oil, soybean oil, etc.) have different sustainability index profiles due to the variation in plantation practice and generation yield [17]. For instance, in the comparison of sustainability performance between palm oil, soybean oil, rapeseed oil and sunflower oil, the study suggests that the production of palm oil has the highest sustainability index profile in land usage due to the relatively high oil generation yield, but performs poorly in deforestation and carbon footprint, while soybean oil production requires the most land, but has the least impact from fertiliser usage. There is no single renewable source that is able to perform well in all the sustainability index profiles. Nonetheless, utilisation of multiple oil crops as process feed has shown significant improvement in the overall sustainability index profile [17]. Additionally, a detailed review of various direct transesterification processes has shown that the majority of the existing technologies are capable of handling a diverse feedstock type [18]. In view of that, there is a research gap to investigate a biodiesel supply chain network that incorporates diverse feedstocks to create a balanced and optimum feedstock sustainability profile. This is critical to address the concern of sustainability issues from high dependence on specific oil crops in biodiesel production, such as extensive deforestation activity from the palm oil plantation or high land usage from soybean plantation. Additionally, diversifying the feedstock could improve the supply chain security issue [19].

This paper aims to address the issue of non-optimum sustainability performance based on the usage of oil crops for biodiesel production by exploring the possibility of incorporating multiple oil crops as the process feed to create a balanced feed sustainability index profile. As mentioned above, the majority of the sustainability concern of oil crop utilisation of biodiesel is coming from the upstream processes like plantation and milling; this paper will only focus on the sustainability performance of 
different oil crops' upstream processes. A mathematical optimisation model is proposed to evaluate the feasibility of incorporating multiple oil crops as process feed for biodiesel production to achieve a better feed sustainability index profile. In order to avoid significant process modification and redesign that will involve high upfront investment, the feedstock selection is based on the limitation of the existing biodiesel production process to handle feed fluctuations. A previous work on biomass supply chain optimisation has tackled a similar problem by introducing a diverse biomass feed selection approach based on existing process technology configurations [20]. The work proposed a biomass selection model based on the biomass element characteristics instead of biomass species. In terms of biodiesel production from oil crops, studies have shown that the efficiency and performance of the process are subjected to the type of feed and the feed properties such as free fatty acid, iodine value and oxidation stability [21-23]. Therefore, the same concept is adopted in this study to investigate the feasibility of integrating multiple oil crops into existing biodiesel processing plants based on the oil crop properties, as well as optimise the overall sustainability index of the feedstock mixture.

\section{Model Formulation}

Superstructure diagrams are used to illustrate the proposed concept of the oil crop supply chain optimisation model for biodiesel production in this work. Figure 1 shows the conventional supply chain of biodiesel production from oil crops. In the conventional approach, the majority of the biodiesel refinery utilises a single source of oil crop as the process feed. This creates the concern of unsustainable sources of certain oil crops based on the oil crops' plantation and refinery processes. For instance, Figure 2 shows the comparison of the sustainability index profile of several major oil crops obtained from previous studies to optimise the oil crop usage to achieve the highest sustainability level [17]. A total of five sustainability aspects were considered, including deforestation, oil yield, fertiliser impact, carbon footprint, and water impact [24-26]. The study compared four main oil crops in the global market, which included palm oil, rapeseed oil, soybean oil and sunflower oil [27-31]. A comparative sustainability index was used to highlight the differences between the sustainability level of each oil crop in the respective sustainability aspect, where $100 \%$ indicates the highest sustainability level and $0 \%$ indicates the lowest sustainability index. For example, oil palm has the highest oil yield at 610 gal of oil/acre, followed by rapeseed oil, sunflower oil and soybean oil at 122 gal of oil/acre, 98 gal of oil/acre and 46 gal of oil/acre, respectively. In the comparative sustainability index, oil palm is indexed at $100 \%$ due to the highest performance, and soybean oil at $0 \%$ due to the lowest oil yield among the oil crops, while rapeseed oil and sunflower oil are indexed at $14 \%$ and $9 \%$, respectively, based on the linear interpolation from the maximum and minimum value [17]. Figure 2 demonstrates the changes in the sustainability index profile between single and multiple oil crops utilisation. For instance, if biodiesel production is solely depending on palm oil, the system will have a significant negative sustainability impact on deforestation and carbon footprint, while production from rapeseed oil only will create high fertiliser impact and land usage due to low oil yield. Alternatively, if the biodiesel production utilised a combination of both oil crops, the produced biodiesel could have a more well-balanced sustainability index profile which subsequently eliminates the possible sustainability problems. The sustainability index profile of the mixed feed is determined based on the weight distribution of the oil crop mixture and their respective sustainability index. Note that in the comparative sustainability index approach, a $0 \%$ index does not imply that it is not acceptable, instead, it represents the performance is the lowest among the peers. For instance, soybean oil is still considered a potential resource for biodiesel production even though it has a score of $0 \%$ in the oil yield index. The comparative sustainability index is used to understand the position of the sustainability level of the process feed among the competing oil crops and the bottleneck of the sustainability profile of each considered oil crop. This can be used to motivate the effort to improve the sustainable practice in all the oil crop industries, as a new breakthrough in any one oil crop's sustainability performance may affect the sustainability index of the rest of the competitive oil crops. Ideally, there is no upper limit of the best sustainability achievement as the requirement is constantly evolving and demanding as the technologies improve. 


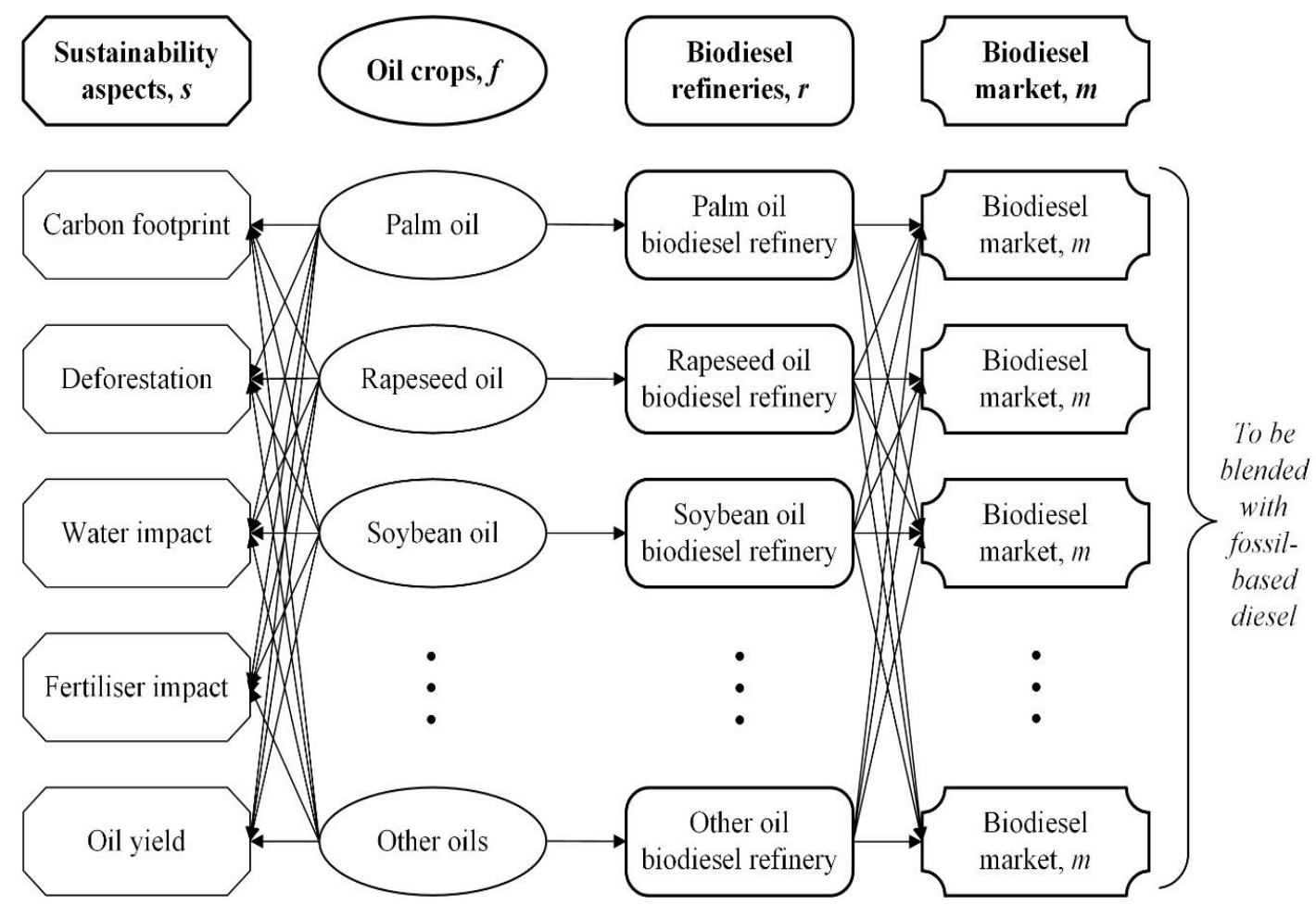

Figure 1. Conventional biodiesel supply chain model.

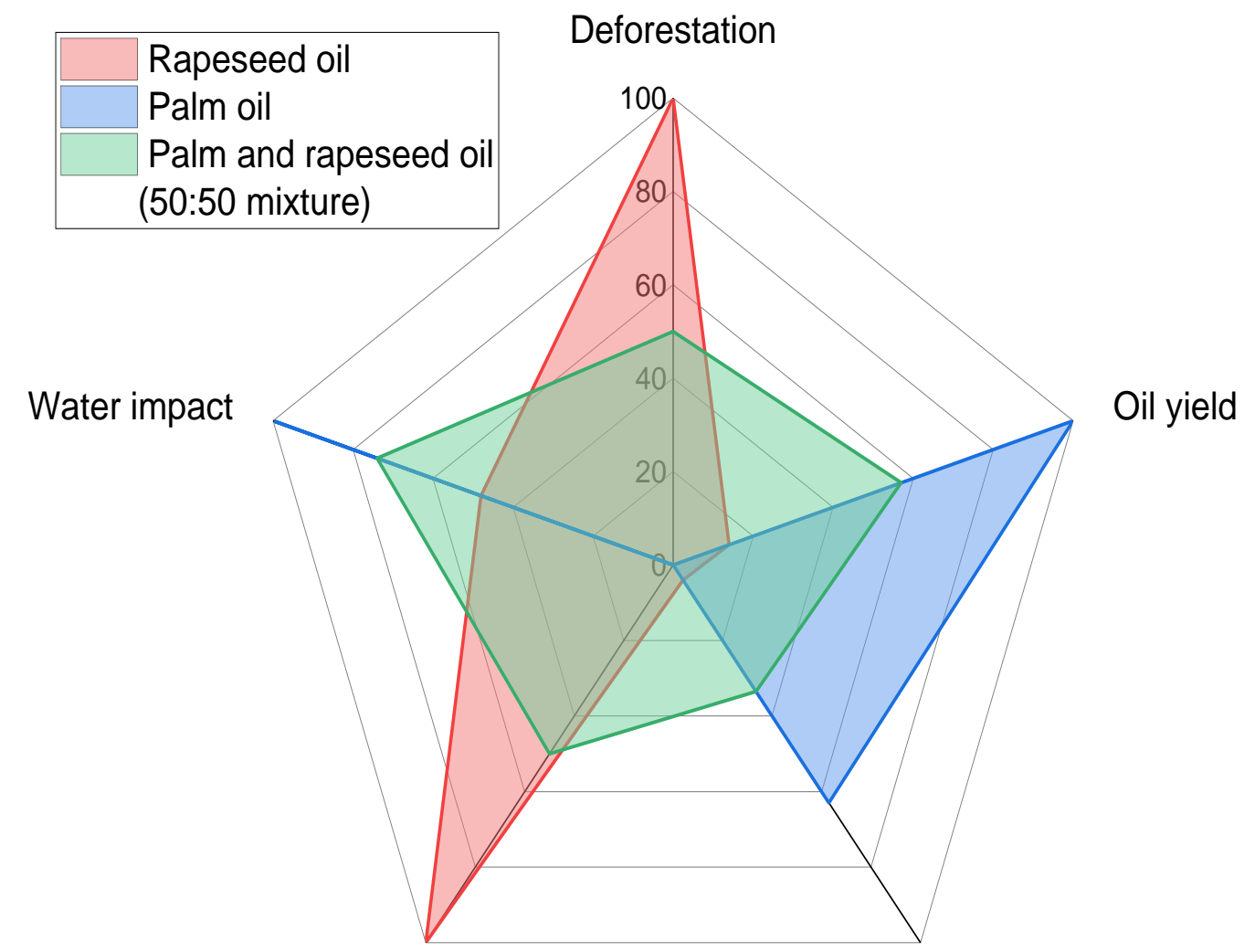

Carbon footprint

Fertiliser impact

Figure 2. Sustainability index profile (in \%) comparison between various types of oil crops [17]. 
Figure 3 shows the proposed model in this paper. The model introduces a novel oil crop selection approach based on bio-oil properties. Instead of limiting specific oil crops as the feedstock of each refinery, the proposed model provides the flexibility of integrating multiple types of oil crops into the existing biodiesel refineries. In order to avoid significant fluctuations in the operation and performance of the biodiesel refineries, only a specific range of bio-oil properties will be accepted in each refinery. This is defined as the properties acceptance range in the context of this paper. The proposed properties acceptance range will be constructed based on the feed properties that would have significant impacts on the production yield and biodiesel quality. For example, the free fatty acid content is considered in this study as part of the feed selection criteria due to the direct influence on the performance of biodiesel production $[32,33]$. Apart from that, the stability of the oil crop and the produced biodiesel is another critical factor in ensuring consistency of the oil and biodiesel quality within the supply chain network. For instance, a study shows that crude palm oil has a shelf life of approximately six months [34]. Iodine value is used to determine total unsaturation within the fatty acid which influences the oxidation stability of the oil crop and the produced biodiesel [35-37]. Estimation of those properties in an oil crop mixture has been proven to correspond to the mixing ratio of the oil crops used in the biodiesel production [38]. These properties would be included as part of the feed selection criteria in the proposed supply chain model to ensure adequate stability of the oil crop and produced biodiesel. Incorporating the feed selection criteria based on the oil crop properties increases the flexibility of the supply chain model to determine the best combination of oil crop utilisation to achieve a feasible and optimal system.

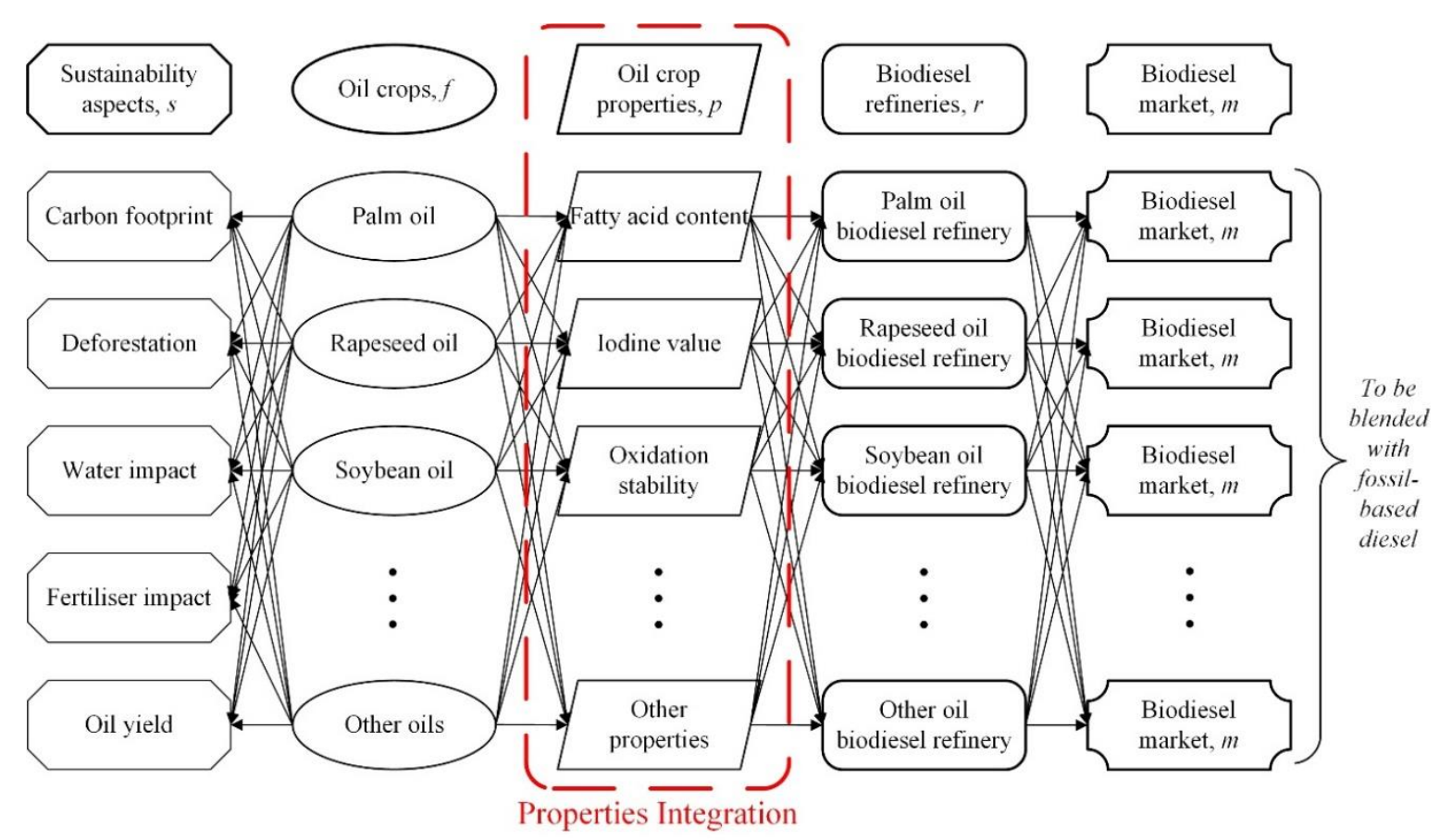

Figure 3. Proposed biodiesel supply chain model integrated with multi-biodiesel selection based on bio-oil properties.

The following describes the model formulation proposed in this study. The model considers (i) mass balance of the supply chain, (ii) oil crop selection based on properties acceptance range, (iii) sustainability profile evaluation and (iv) cost consideration. Equations (1)-(5) describe the mass balance of the material logistics in the supply chain system. Equation (1) indicates that the total transported oil crops, $\sum_{f} \mathrm{Oil}_{f, r}$ should be less than or equal to the availability of the oil crops, $\mathrm{O}_{f}$, from each resource location, $f$. In this context, each resource location is restricted to a single type of oil crop availability. Equation (2) determines the total oil crops received as process feed, $F_{r}$, in the 
respective biodiesel refineries, $r$. The production rate of biodiesel is governed by Equation (3), where the produced biodiesel, $D_{r}$, in each biodiesel refineries, $r$, is calculated based on a fixed biodiesel conversion yield, $\mathrm{X}_{r}$, based on the total oil crop received as the process feed, $F_{r}$. Similar to Equation (1), Equation (4) limits the transportation of produced biodiesel, $\sum_{m}$ Biodiesel $_{r, m}$, to be not more than the produced biodiesel in the respective biodiesel refineries. Lastly in material balance, Equation (5) indicates that all biodiesel demand, $\mathrm{M}_{m}$, is required to be fulfilled in the supply chain network.

$$
\begin{gathered}
\sum_{r} \text { Oil }_{f, r} \leq \mathrm{O}_{f} \quad \forall f \in F \\
\sum_{f} \text { Oil }_{f, r}=F_{r} \\
F_{r} \times \mathrm{X}_{r}=D_{r} \quad \forall r \in R \\
\sum_{m} \text { Biodiesel }_{r, m} \leq D_{r} \quad \forall r \in R \\
\sum_{r} \text { Biodiesel }_{r, m}=\mathrm{M}_{m} \quad \forall r \in R
\end{gathered}
$$

The second part of the model is to include the process feed selection based on oil crop properties. The respective oil crop properties, $p$, from each resource, $f$, is presented as $\mathrm{P}_{p, f}$ and the selection of the feed is bounded by the property acceptance range in respective biodiesel refineries. This acceptance range is proposed based on the natural oil crop properties' fluctuation in a typical supply chain system and the original oil crop species used in the refinery. For example, the fluctuation of palm oil properties would be used as the basis to form the acceptance range for a palm-oil-based biodiesel refinery. Equations (6) and (7) limit the feed selection based on the upper and lower properties range, $\mathrm{P} \_u p_{p, r}$ and P_low ${ }_{p, r}$, respectively.

$$
\begin{array}{ll}
\sum_{f}\left(\text { Oil }_{f, r} \times \mathrm{P}_{p, f}\right) \leq \mathrm{P}_{\mathrm{up}_{p, r}} \times F_{r} & \forall p, r \in P, R \\
\sum_{f}\left(\text { Oil }_{f, r} \times \mathrm{P}_{p, f}\right) \geq \mathrm{P}_{\text {low }_{p, r}} \times F_{r} & \forall p, r \in P, R
\end{array}
$$

Apart from the oil crop properties integration, the following equation represents the sustainability consideration of the model. The focus of this paper is to evaluate the possibility of producing a balanced sustainability index profile in each biodiesel refinery by utilising diverse oil crop feed (with each unique sustainability index profile) in order to tackle the sustainable concern of over usage of a specific oil crop. Therefore, the proposed formulation focusses on the sustainability index profile contributions from feed selection, in other words, the supply chain network between each resource and the biodiesel refinery, $\mathrm{Oil}_{f, r} . \mathrm{S}_{s, f}$ represents the sustainability index, s, of the respective oil crop from each resource, $f$. Equation (8) governs that the combined sustainability profile of the feed used to produce biodiesel should be higher than a specific sustainability index limit, S_limit $t_{s, r}$. Depending on the regional legislation, the sustainability limit can be modified to ensure the proposed supply chain solution achieves the sustainability standard. Note that the sustainability index proposed in this model is associated with the type and origin of the oil crops. The index only considers the upstream processes of oil crops such as plantation and milling processes. Sustainability contributions from logistics and refineries are not included as part of the study in order to highlight the sustainability impact of biodiesel production from the feed selection.

$$
\sum_{f}\left(\mathrm{Oil}_{f, r} \times \mathrm{S}_{s, f}\right) \geq \mathrm{S}_{\mathrm{limit}_{s, r}} \times F_{r} \quad \forall s, r \in S, R
$$

Lastly, the model also considers the economic aspect of the supply chain. Equations (9)-(11) show the cost calculation for oil cost, Oil_Cost; production cost, Pro_Cost; and transportation cost, Log_Cost, where $C_{f}$ refers to the unit cost for each oil crop; $C_{r}$ denotes the production cost per unit of biodiesel produced in each refinery; while $\mathrm{L}_{-} \mathrm{C}_{f, r}$ and $\mathrm{L}_{-} \mathrm{C}_{r, m}$ refer to the unit transportation cost of oil crop and 
biodiesel, respectively. The logistics cost in Equation (11) considered the distance between the source and destination and the transportation mode, such as land and sea travels. Equation (12) shows the total cost considered in the model.

$$
\begin{gathered}
\sum_{f, r}\left(\operatorname{Oil}_{f, r} \times \mathrm{C}_{f}\right)=\text { Oil_Cost } \\
\sum_{r}\left(D_{r} \times \mathrm{C}_{r}\right)=\text { Pro_Cost } \\
\sum_{f, r}\left(\text { Oil }_{f, r} \times \mathrm{L}_{-} \mathrm{C}_{f, r}\right)+\sum_{r . m}\left(\text { Biodiesel }_{r, m} \times \mathrm{L}_{-} \mathrm{C}_{r, m}\right)=\text { Log_Cost } \\
\text { Oil_Cost }+ \text { Pro_Cost }+ \text { Log_Cost }=\text { Total_Cost }
\end{gathered}
$$

Two objective functions (different scenarios) are proposed to be investigated based on the proposed model. First, the biodiesel supply chain problem can be optimised by minimising the Total_Cost (Equation (12)) to determine the sustainability index profile of each refinery feed at the lowest cost. Apart from that, the model can be used to optimise the overall sustainability score (Equation (14)) of the system. Equations (13) and (14) show the calculation of the respective sustainability score of the refinery feed, S_Score $e_{s, r}$, and the overall sustainability score, S_Overall_Score, of the system. Sustainability factors, $S_{-}$weightage $e_{s, r}$, are introduced to indicate the weightage distribution of the importance of sustainability aspects, $s$, in the respective refinery, $r$. Each refinery can have its own weightage distribution based on the regional sustainability requirement and policy. For instance, a weightage of 0.2 can be assigned to each sustainability aspect (total of five) shown in Figure 2 if all aspects are equally important. Alternatively, higher weightage can be assigned for specific sustainability aspects based on the development direction or legislation requirement to give priority on a specific sustainability aspect.

$$
\begin{gathered}
\sum_{f}\left(\text { Oil }_{f, r} \times \mathrm{S}_{s, f}\right)=S_{-} \text {Score }_{s, r} \quad \forall s, r \in S, R \\
\sum_{s, r}\left(\text { S_Score }_{s, r} \times \text { S_weightage }_{s, r}\right)=\text { S_Overall_Score }
\end{gathered}
$$

Since the sustainability score is calculated based on the multiplication of the number of oil crops and their respective sustainability index, the range of sustainability scores presented in Equations (13) and (14) will not be the same as the sustainability index, which is in the range of $0 \%$ to $100 \%$. In order to provide a better perspective and comparison of the improved feed sustainability, the optimised sustainability score is converted into a sustainability index format by dividing the score with the total amount of feed used. Equation (15) shows the sustainability index profile for each refinery, S_Profile $e_{s, r}$, and Equation (16) shows the overall sustainability index of the system, Overall_S_Index. These calculations were conducted outside of the optimisation model to simplify the model from a non-linear problem to a linear problem.

$$
\begin{aligned}
& \frac{S \_ \text {Score }_{s, r}}{F_{r}}=S \_ \text {Profile } e_{s, r} \quad \forall s, r \in S, R \\
& \frac{S \_ \text {Overall_Score }}{\sum_{r} F_{r}}=\text { Overall_S_Index }
\end{aligned}
$$

\section{Case Study and Discussions}

Case studies were constructed to investigate the impact on the sustainability profile of the produced biodiesel from biodiesel refineries by considering multiple types of oil crops as the process feed. Key oil crops, namely, palm oil, rapeseed oil, soybean oil, and sunflower oil were considered in the case study due to their relatively high production rates to minimise competition with the food supply chain. Several assumptions and simplifications were made to enable a more focused discussion on the 
integration of multiple oil crops to improve sustainability performance. The information presented was obtained from the literature and online sources to simulate some of the critical elements from the actual biodiesel industry to showcase the functionality of the proposed model.

\subsection{Description of Case Study}

Table 1 shows the information of the key oil crop availability; Table 2 tabulates the conventional feed and conversion yield of each biodiesel refinery and Table 3 summarises the information of biodiesel demand considered in this case study. The selection of data is based on the availability of the multiple key oil crops, the regional biodiesel refinery plants and petrodiesel refinery to mix the produced biodiesel as a fuel. The production cost of each biodiesel refinery is assumed to be at the same rate of USD $131.19 \mathrm{t}^{-1}$ [39]. The sea and land shipping costs of the oil crops and biodiesel were assumed to be at a fixed cost of USD $1.21 \mathrm{~km}^{-1} \cdot \mathrm{t}^{-1}$ and USD $1.00 \mathrm{~km}^{-1} \cdot \mathrm{t}^{-1}$, respectively [40].

Table 1. Oil crop resources [41].

\begin{tabular}{ccccc}
\hline Oil Crops, $f$ & Species & Location & Availability $\left(\mathbf{t} \cdot \mathbf{y}^{\mathbf{- 1})}\right.$ & Price $_{\left(\mathbf{U S D} \cdot \mathbf{t}^{-\mathbf{1}}\right)}$ \\
\hline F1 & Rapeseed oil & Sichuan, China & $5,700,000$ & 912.38 \\
F2 & Soybean oil & Heilongjiang, China & $11,700,000$ & 766.32 \\
F3 & Palm oil & Hainan, China & 233,190 & 684.62 \\
F4 & Sunflower oil & Inner Mongolia, China & 299,850 & 777.41 \\
F5 & Palm oil & Johor, Malaysia & $19,670,000$ & 684.62 \\
F6 & Rapeseed oil & Odessa, Ukraine & 101,050 & 912.38 \\
F7 & Soybean oil & Khmelnytskyi, Ukraine & 154,400 & 776.32 \\
F8 & Sunflower oil & Dnipropetrovsk, Ukraine & $4,400,000$ & 777.41 \\
\hline
\end{tabular}

Table 2. Biodiesel refineries.

\begin{tabular}{cccc}
\hline Biodiesel Refineries, $\boldsymbol{R}$ & Conventional Feed & Location & Biodiesel Yield (\%) [22] \\
\hline R1 & Rapeseed oil & Sichuan Gushan Oil Chemical Co., China & 98.0 \\
R2 & Soybean oil & China Petrochemical Corporation, China & 98.0 \\
R3 & Palm oil & Sime Darby, Malaysia & 97.0 \\
R4 & Sunflower oil & Oriana-Galel Chemical Enterprise, Ukraine & 95.7 \\
\hline
\end{tabular}

Table 3. Biodiesel market demand [42,43].

\begin{tabular}{ccc}
\hline Biodiesel Market, $\mathbf{M}$ & Location & Demand $\left(\mathbf{t} \cdot \mathbf{y}^{\mathbf{- 1}}\right)$ \\
\hline M1 & Sinopec Zhenhai Refinery, China & 827,789 \\
M2 & Sime Darby Oil Langat Refinery, Malaysia & 900,000 \\
M3 & Kremenchuk Oil Refinery, Ukraine & $900,000^{\text {a }}$ \\
\hline \multicolumn{3}{c}{}
\end{tabular}

The transportation cost to deliver the oil crops and produced biodiesel are summarised in Tables 4 and 5. The summarised costs took into account the distance, inland transportation by truck and sea transportation by ship. The properties and sustainability index profile of each oil crop are listed in Tables 6 and 7, respectively. The properties acceptance range for each biodiesel refinery was assumed to be $\pm 10 \%$ based on the properties of the conventional feed (in Table 2). The ranges were set to replicate the typical acceptable fluctuation range of oil crops' properties and to ensure the processes can handle multiple types of feed without major modification of the processing parameters. A study has shown that the advancement of biodiesel production technology, such as catalytic and pretreatment processes, enables refineries to cater to various types of oil crops in production [44]. Nonetheless, a detailed investigation of the flexibility of respective refineries should be conducted prior to the actual implementation of the feed mixing to avoid significant process performance deviation due to the change of feed properties. Often, the investigation of the refinery feed flexibility requires numerous pilot and large scale experiment efforts and investment cost. The result from this optimisation model 
can be used as the basis to understand the extent of improvement in terms of cost and sustainability performance by integrating multiple oil crops prior the decision to investigate the properties acceptance range. The sustainability index profiles in Table 7 are obtained from the previous study to compare the sustainability performance of the list of oil crops [17]. The sustainability index profile is presented in the comparative data among the four types of oil crops. For example, palm oil scores $100 \%$ in oil yield and water impact indices, indicating that it is performing the best in generating the most oil and uses the least water compared to the other oil crops. In contrast, $0 \%$ on palm oil deforestation and carbon footprint indices are indicating that it has the worst sustainability achievement in these aspects among the four types of oil crop. All the presented sustainability aspects were assumed to be equally important; hence, the weightage of all sustainability factors in each refinery was assigned as 0.2 in all case studies.

Table 4. Logistic cost of transporting oil crops to biodiesel refineries in USD $\mathrm{t}^{-1}$.

\begin{tabular}{ccccc}
\hline Oil Crops, $\boldsymbol{F}$ & R1 & R2 & R3 & R4 \\
\hline F1 & 311.73 & 2215.87 & 6401.60 & $10,084.94$ \\
F2 & 3232.46 & 2722.18 & 6849.34 & $10,532.68$ \\
F3 & 1720.47 & 2031.21 & 6365.86 & $10,049.20$ \\
F4 & 2133.47 & 1988.52 & 6118.66 & 9802.00 \\
F5 & 6471.79 & 4833.72 & 342.51 & $11,082.94$ \\
F6 & 9030.72 & 7392.65 & 9958.53 & 790.25 \\
F7 & 9576.65 & 7938.57 & $10,504.45$ & 240.25 \\
F8 & 9478.36 & 7840.29 & $10,406.17$ & 1080.13 \\
\hline
\end{tabular}

Table 5. Logistic cost of transporting biodiesel from refineries to markets in USD $\cdot \mathrm{t}^{-1}$.

\begin{tabular}{cccc}
\hline Oil Crops, $\boldsymbol{F}$ & M1 & M2 & M3 \\
\hline R1 & 1976.61 & 6131.76 & 9486.30 \\
R2 & 1.49 & 4493.69 & 7848.23 \\
R3 & 4501.44 & 7.45 & $10,414.11$ \\
R4 & 8184.780723 & $10,742.91566$ & 928.2409639 \\
\hline
\end{tabular}

Table 6. Properties of oil crops $[38,45,46]$.

\begin{tabular}{|c|c|c|c|c|}
\hline Oil Crops Type & $\begin{array}{l}\text { Iodine Value } \\
\left(\mathrm{g} \mathrm{I}_{2} \cdot 100 \mathrm{~g}^{-1}\right)\end{array}$ & $\begin{array}{l}\text { Peroxide Value } \\
\left(\text { meq } \mathrm{O}_{2} \cdot \mathbf{k g}^{-1}\right)\end{array}$ & $\begin{array}{l}\text { Saturated Fatty } \\
\text { Acid (\%) }\end{array}$ & $\begin{array}{c}\text { Unsaturated Fatty } \\
\text { Acid (\%) }\end{array}$ \\
\hline Rapeseed oil & 116 & 5.73 & 7.6 & 92.4 \\
\hline Soybean oil & 128 & 2.40 & 19.7 & 84.5 \\
\hline Palm oil & 51 & 28.02 & 43.4 & 56.6 \\
\hline Sunflower oil & 135 & 6.32 & 11.6 & 88.4 \\
\hline
\end{tabular}

Table 7. Sustainability index profile of oil crops [17].

\begin{tabular}{cccccc}
\hline \multirow{2}{*}{$\begin{array}{c}\text { Oil Crops } \\
\text { Type }\end{array}$} & Deforestation & Oil Yield & $\begin{array}{c}\text { Fertiliser } \\
\text { Impact }\end{array}$ & $\begin{array}{c}\text { Carbon } \\
\text { Footprint }\end{array}$ & Water Impact \\
\cline { 2 - 5 } & 100 & 14 & 4 & 100 & 48 \\
Rapeseed oil & 36 & 0 & 100 & 0 & 54 \\
Soybean oil & 0 & 100 & 63 & 0 & 100 \\
Palm oil & 88 & 9 & 0 & 72 & 0 \\
Sunflower oil & & & & & \\
\hline
\end{tabular}

The case study was solved using the General Algebraic Modelling System with CPLEX solver for a linear programming model consisting of 317 equations and 302 variables. All the cases were solved within $1 \mathrm{~s}$ in a Windows 10 computer with an Intel Core i5 $1.6 \mathrm{GHz}$ processor and $4 \mathrm{~GB}$ 
RAM. A total of four main scenarios were simulated: Case 1-minimising cost with the conventional approach where each refinery only accept the conventional feed as per Table 2, Case 2-minimising cost (without sustainability limit constraint) with the proposed model which allows mixing of multiple oil crops as refineries' feed based on the properties acceptance ranges, Case 3-maximising overall sustainability score of the system with the proposed model, and Case 4-minimising cost with sustainability limit and integration of multiple oil crops. As the novelty of this paper focuses on the integration of multiple oil crops feeds in refineries to improve the profit and sustainability index profile of the system, the main discussion below highlights the selection and distribution of oil crops in each refinery feed.

\subsection{Case 1: Conventional Integration Approach}

This section describes the result obtained for Case 1 where the optimum solution is obtained with the minimum overall cost of production at USD $6.57 \mathrm{billion} \cdot \mathrm{y}^{-1}$ to fulfil the market demands. Table 8 shows the selection of oil crops for each refinery, where only the conventional type of oil crop was selected as feed. The result demonstrates that the limitation of the conventional supply chain model was not able to integrate the mixing of multiple types of oil crops as the process feed. In addition, no production was proposed in R2 due to the relatively higher transportation cost of transporting oil crops to R2 compared to R1. Figure 4 shows the sustainability profile of each refinery feed for Case 1 result. Due to the restriction of the feed selection, it is observed that the sustainability profile of the refinery feed was subject to the sustainability profile of the conventional oil crop type. This is an excellent example to reflect the current situation of biodiesel production. For example, R3, a palm oil-based biodiesel refinery, suffers from a critically low score in deforestation and carbon footprint. This has been a renowned issue in the industry for many years. However, it is a very challenging problem to be solved as it is difficult to control and educate a vast number of small- and medium-size plantation stakeholders to adapt to a more sustainable practice.

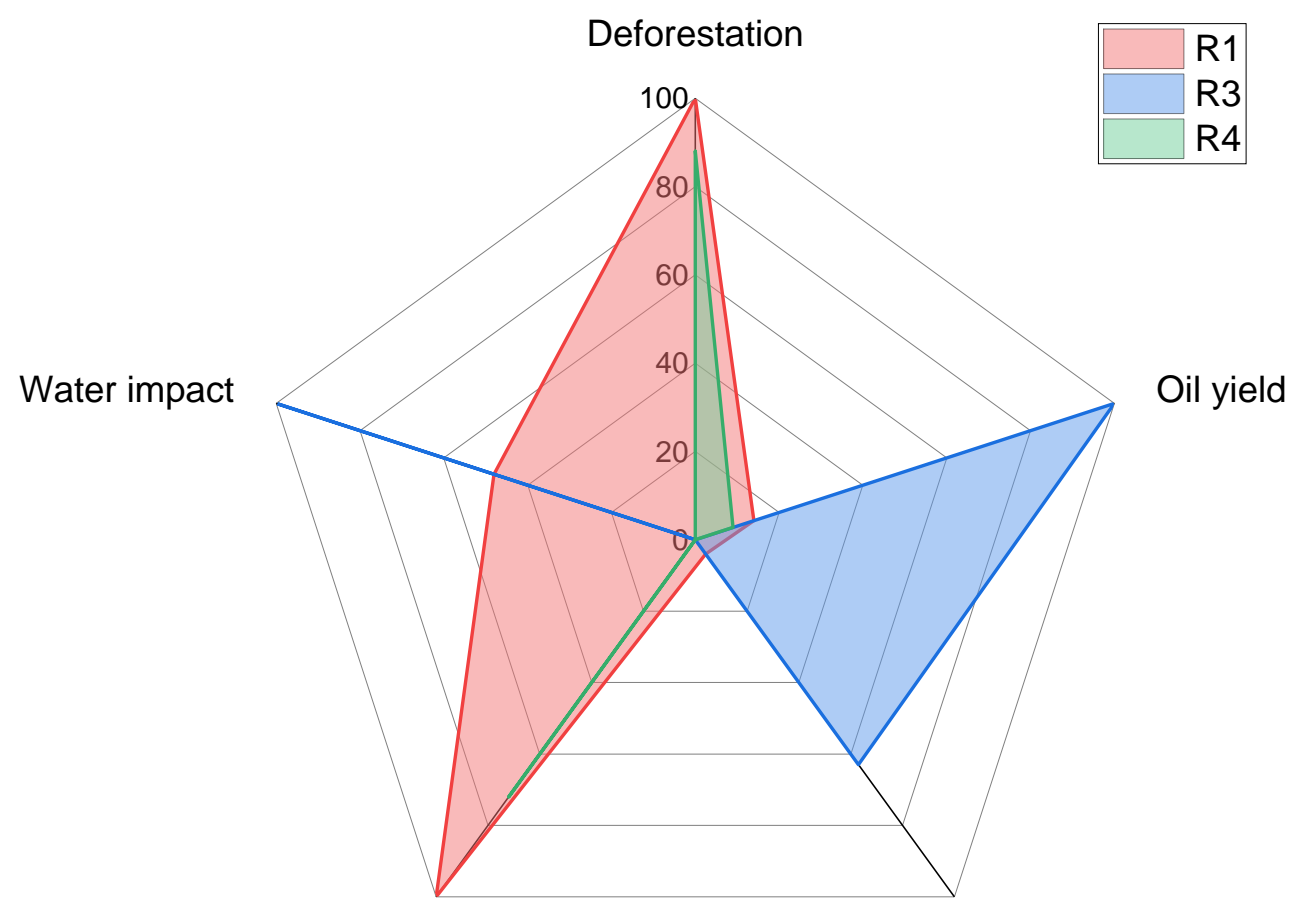

Carbon footprint

Fertiliser impact

Figure 4. Sustainability profile of refineries feeds for Case 1. 
Table 8. Feed distribution of each refinery in Case 1.

\begin{tabular}{cccc}
\hline \multirow{2}{*}{ Biodiesel Refineries, $\boldsymbol{R}$} & \multicolumn{3}{c}{ Oil Crops, $\mathbf{F}\left(\mathbf{t} \cdot \mathbf{y}^{-\mathbf{1}}\right)$} \\
\cline { 2 - 4 } & $\mathbf{F 1}$ & $\mathbf{F 5}$ & F8 \\
\hline R1 & 844,683 & - & - \\
R3 & - & 927,835 & - \\
R4 & - & - & 940,438 \\
\hline
\end{tabular}

\subsection{Case 2: Properties Integration Approach-Minimising Cost}

Case 2 considered in this study investigated the impact of integrating multiple types of oil crops as process feed to improve sustainability performance. The minimum cost of production was determined at USD 6.43 billion $\cdot \mathrm{y}^{-1}$, approximately $2.2 \%$ lower than Case 1 . Table 9 shows the feed distribution of the respective refineries. The result shows that the best feed for R1 and R3 remained rapeseed oil and palm oil, respectively. Interestingly, the feed for R4 was recommended to use the combination of rapeseed, soybean, and sunflower oil. The combination of feed enabled cost reduction due to the lower cost of soybean oil while fulfilling the properties acceptance range of R4. Since the objective of Case 2 is to minimise cost with the proposed properties integration, no significant improvement was found in the feed sustainability profile of each refinery as shown in Figure 5. The fertiliser and water impact indices have been improved to approximately $15 \%$ and $13 \%$, respectively, compared to $4 \%$ in Case 1 .

Table 9. Feed distribution of each refinery in Case 2.

\begin{tabular}{cccccc}
\hline \multirow{2}{*}{ Biodiesel Refineries, $\boldsymbol{R}$} & \multicolumn{5}{c}{ Oil Crops, $\mathbf{F}\left(\mathbf{t} \cdot \mathbf{y}^{-\mathbf{1}}\right)$} \\
\cline { 2 - 6 } & F1 & F5 & F6 & F7 & F8 \\
\hline R1 & 844,683 & - & - & - & - \\
R3 & - & 927,835 & - & - & - \\
R4 & - & - & 101,050 & 136,412 & 702,976 \\
\hline
\end{tabular}

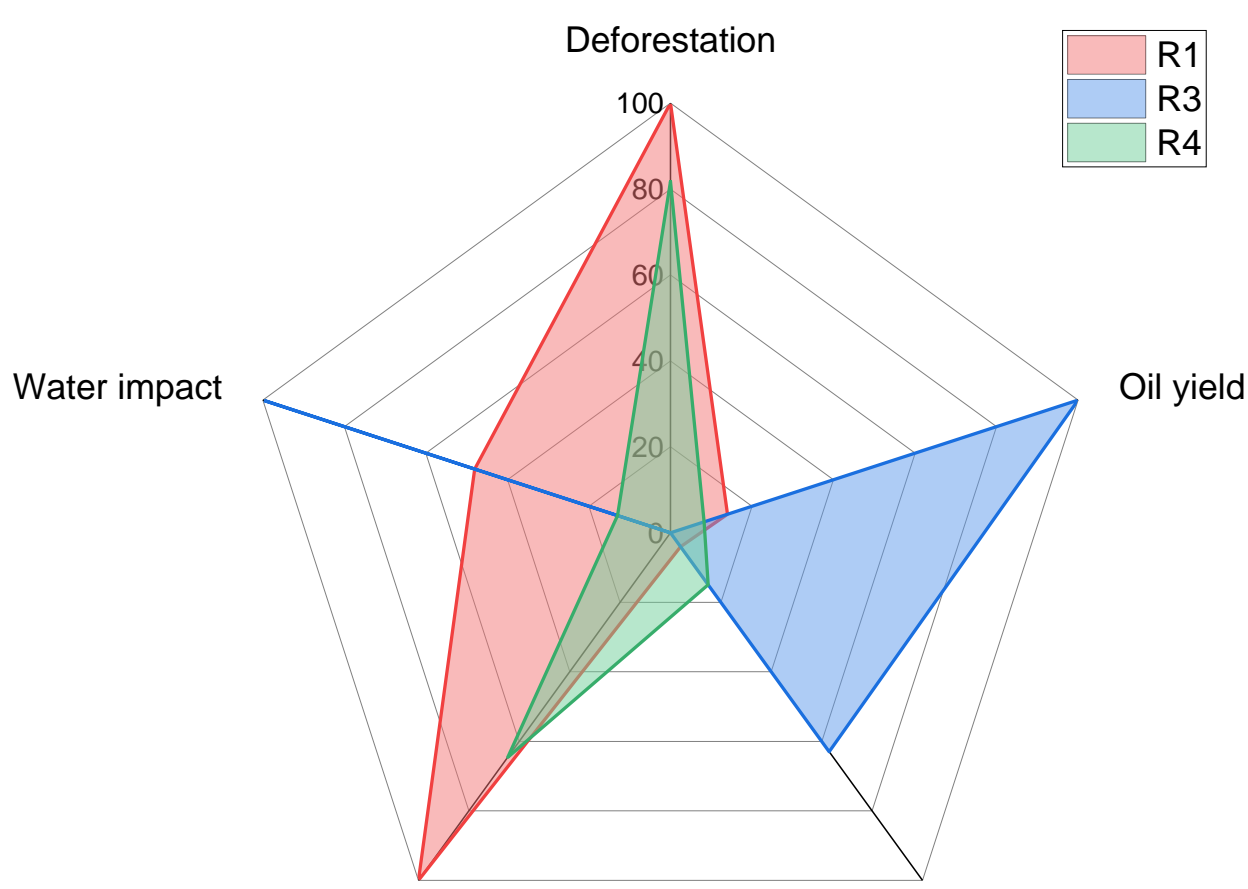

Carbon footprint

Fertiliser impact

Figure 5. Sustainability profile (in \%) of refineries feed for Case 2. 


\subsection{Case 3: Properties Integration Approach-Maximising the System Overall Sustainability Score}

To investigate the functionality of the proposed model to improve the sustainability index profile of the biodiesel refinery feed, Case 3 was constructed to maximise the overall sustainability score of the system instead of minimising the production cost. The sustainability limit for each index was set at $0 \%$ to investigate the maximum overall sustainability index of the system. Interestingly, the model shows that utilising only rapeseed oil in R1 would generate the best overall sustainability index at $53.2 \%$. The total production cost is increased to USD 19.33 billion $\cdot \mathrm{y}^{-1}$ due to the high cost of rapeseed oil and transportation cost to a centralised processing plant. Nonetheless, the solution is not practical to solve the sustainability issue in the industry as utilising rapeseed oil alone for biodiesel production would have a relatively high negative fertiliser impact (at only $4 \%$ as shown in Table 7). Additionally, note that the optimum sustainability index calculation is only based on the sustainability index profile of oil crops upstream processes where the sustainability contributions from logistic and refinery were not considered in this study. In order to avoid an overly low sustainability index of any of the aspects, two sensitivity analysis cases, Case 3.1 and Case 3.2, were conducted to investigate the changes in the overall sustainability performance by increasing the sustainability limit from $0 \%$ to $10 \%$ and $15 \%$, respectively. Referring to Equation (8), this means that each of the sustainability aspects of the refinery feed must have a minimum index of the indicated limit. Note that approximately $15.7 \%$ (of the sustainability limits) is the bottleneck of the system to generate a feasible solution due to the constraint in properties acceptance range to avoid significant modifications in the refinery's operation.

Table 10 compares the refinery feed distribution in Cases 3, 3.1 and 3.2. The optimum overall sustainability indices of the system were found to be at $53.2 \%, 52.3 \%$ and $44.5 \%$, respectively. In all the cases which maximise the overall sustainability index, the model proposed to utilise only a single refinery plant to ensure a high sustainability level. The model prioritised the utilisation of rapeseed oil in $\mathrm{R} 1$ since rapeseed oil has the highest overall sustainability score among the key oil crops considered in this study. It is observed that more oil crops were integrated as the process feed when the sustainability limits were increased. All rapeseed, soybean, palm and sunflower oils were proposed to be used as the refinery feed to achieve a minimum of $15 \%$ in all the sustainability indices. Despite the reduction of the overall sustainability index of the system, Figure 6 shows that increasing the sustainability limit was able to generate a more balanced sustainability index profile where both the oil yield and fertiliser impact indices had been successfully increased to approximately $15.7 \%$ in Case 3.2. This could be a potential solution for the industry to address the concern of overly poor sustainability practices in a specific aspect. For example, the integration of alternative oil crops in a palm biodiesel refinery can be conducted to address the concern of high deforestation and carbon footprint problem. Nonetheless, the results show that the overall production cost for Case 3.1 and 3.2 increased to USD 19.78 billion $\cdot \mathrm{y}^{-1}$ and USD $39.90 \mathrm{billion} \cdot \mathrm{y}^{-1}$, respectively. This shows that although the proposed approach was able to generate a biodiesel production system with a more well-rounded sustainability index profile, the impact on the production cost was significant. Despite the higher cost in production, the proposed integration approach can provide an immediate solution for refineries to produce more sustainably-balanced biodiesel. However, the additional production cost should be taken into consideration to ensure the feasibility of implementation.

Table 10. Feed distribution of each refinery in Case 3.

\begin{tabular}{ccccccc}
\hline \multirow{2}{*}{ Case } & \multirow{2}{*}{ Biodiesel Refineries, $\boldsymbol{R}$} & \multicolumn{5}{c}{ Oil Crops, $\mathbf{F}\left(\mathbf{t} \cdot \mathbf{y}^{-\mathbf{1}}\right)$} \\
\cline { 3 - 7 } & & F1 & F2 & F3 & F4 & F8 \\
\hline 3 & R1 & $2,681,417$ & - & - & - & - \\
3.1 & R1 & $2,513,574$ & 167,182 & 662 & - & - \\
3.2 & R4 & $1,153,781$ & 277,685 & 157,184 & 299,580 & 85,360 \\
\hline
\end{tabular}




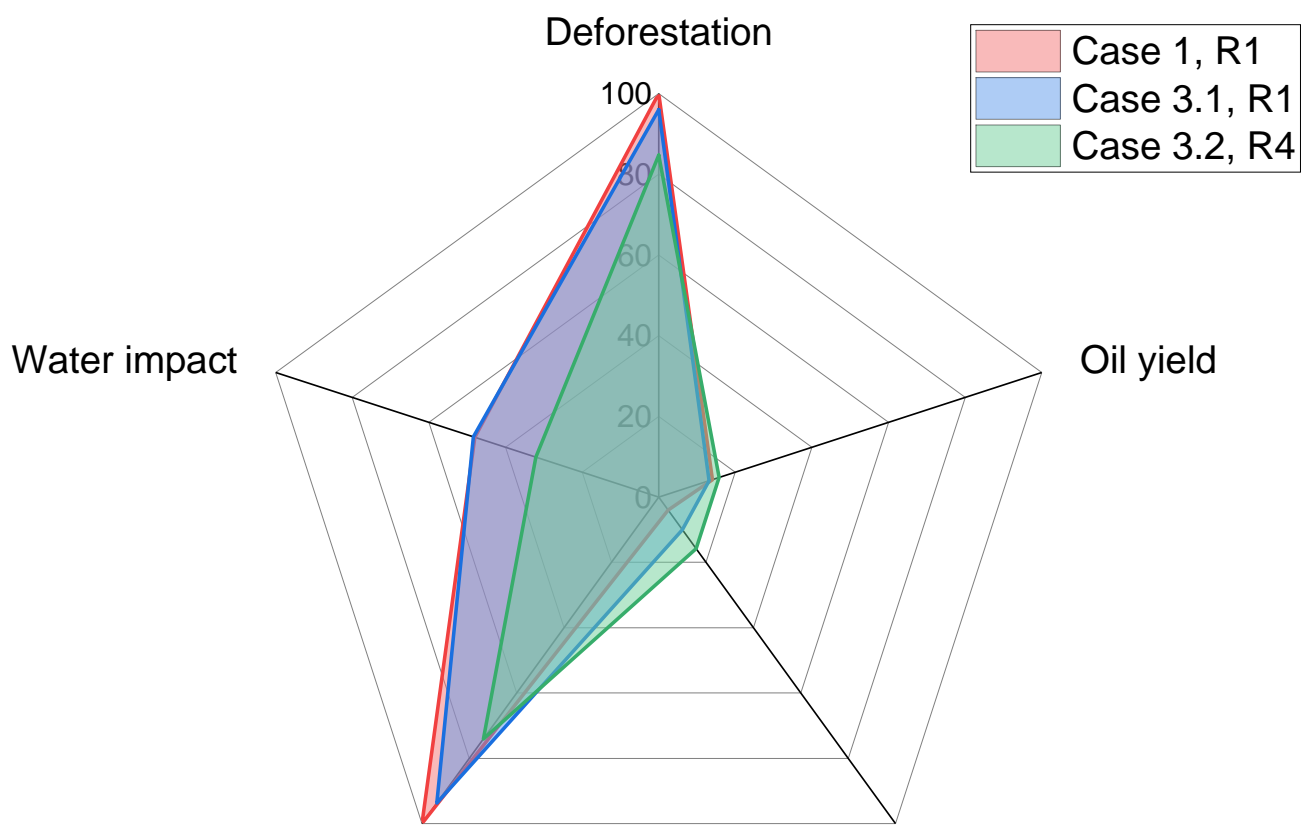

Carbon footprint

Fertiliser impact

Figure 6. Sustainability profile (in \%) of refineries feed for Cases 3, 3.1 and 3.2.

\subsection{Case 4: Properties Integration Approach—Minimising Cost with Sustainability Limit}

To address the issue of high production costs in a sustainability balanced system, Case 4 was constructed to determine the lowest cost of production for the proposed biodiesel system with $15 \%$ of the sustainability limit (Table 11). Compared to Case 3.2, the result obtained from Case 4 shows improvement in the overall production cost with the reduction from USD $39.90 \mathrm{billion} \cdot \mathrm{y}^{-1}$ to USD 34.31 billion $\cdot \mathrm{y}^{-1}$. The proposed solution reduces the importation of oil crops to minimise the transportation cost and utilises less rapeseed oil as the process feed due to the higher price. Although the carbon footprint from logistics is not considered in this work, the reduction of importation in cost minimisation cases indirectly helps to reduce the carbon footprint from logistics. Compared to Case 3.2 that maximises the overall sustainability index with a sustainability limit of $15 \%$, the overall sustainability index of the system in Case 4 did not have significant changes at $44.1 \%$, compared to 44.5\% in Case 3.2. Figure 7 shows the comparison of the sustainability index profile of both cases is almost identical. Note the proposed result is based on the assumption that the refinery process is subjected to $\pm 10 \%$ for the properties acceptance range, which is the bottleneck of the system. If the flexibility of the process can be improved to accept more varieties of feed, for example, $\pm 20 \%$ of the properties acceptance range, Case 4 can be solved with an improved sustainability limit at $21 \%$ instead of $15 \%$. This shows that the flexibility of the biodiesel refinery process to handle a wider variety of feed will directly affect the feasibility of the biodiesel system to achieve a balanced feed sustainability index profile. Apart from that, the high production cost demonstrated in the case studies can be improved if more oil crops within the region were considered. The case studies presented were focused only on the relatively high yield oil crops in China, Malaysia and Ukraine which limits the selection of the process feed. Consideration of more oil crops, such as coconut oil and peanut oil, and countries like Indonesia, Thailand and the United States would further enhance the accuracy of the model to reflect the actual scenario. 
Table 11. Feed distribution of each refinery in Case 4.

\begin{tabular}{ccccccc}
\hline \multirow{2}{*}{ Biodiesel Refineries, $\boldsymbol{R}$} & \multicolumn{7}{c}{ Oil Crops, F (t· $\left.\mathbf{y}^{-\mathbf{1}}\right)$} \\
\cline { 2 - 7 } & $\mathbf{F 1}$ & F2 & F3 & F6 & F7 & F8 \\
\hline R4 & 999,869 & 123,553 & 160,115 & 101,050 & 154,400 & $1,206,874$ \\
\hline
\end{tabular}

\section{Deforestation}

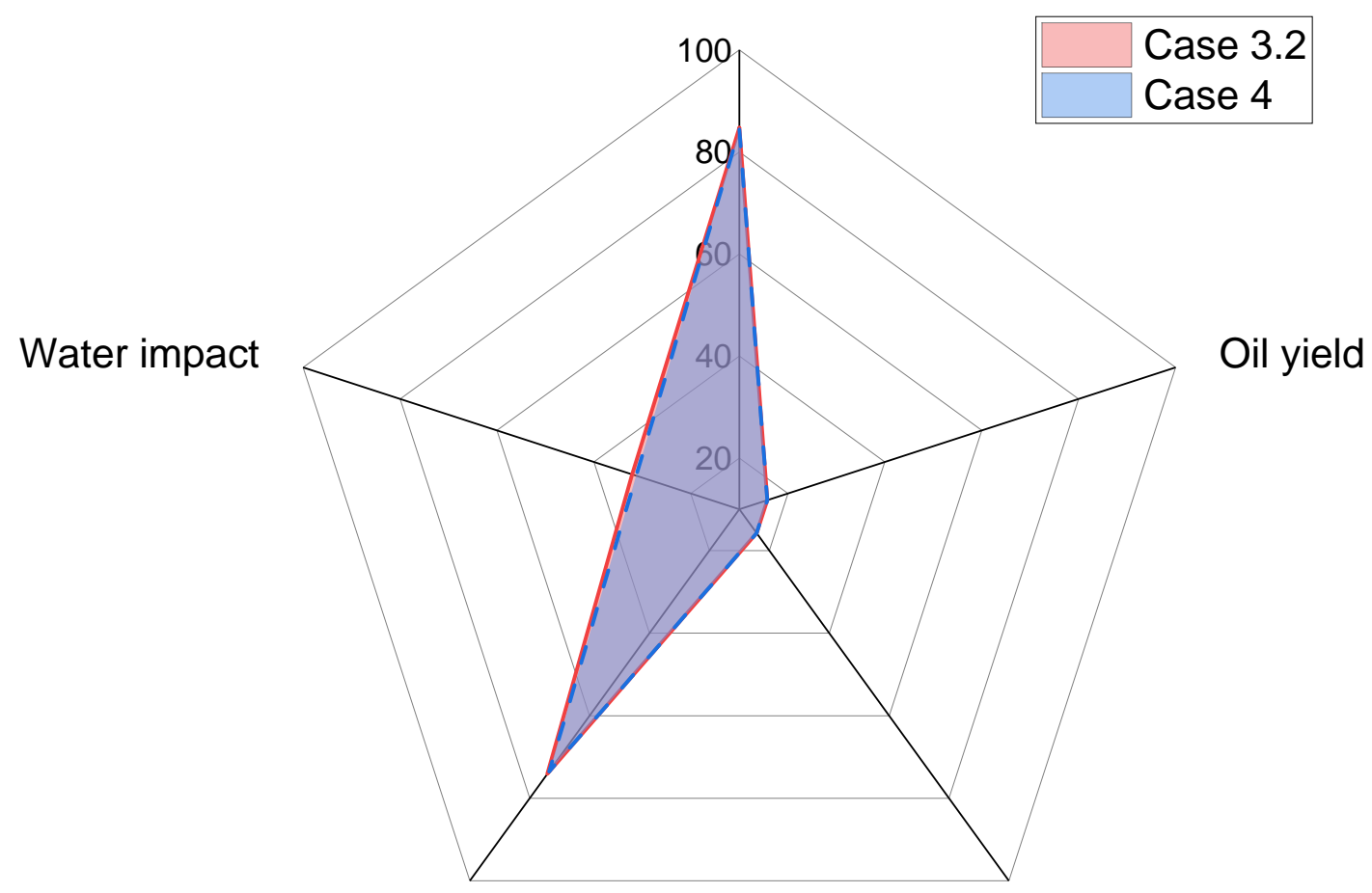

\section{Carbon footprint}

Fertiliser impact

Figure 7. Sustainability profile (in \%) of refineries feed for Case 3.2 and 4.

\subsection{Applicability of the Proposed Model}

Previous sections have demonstrated the comparison between the conventional biodiesel supply chain and the proposed multi-feed biodiesel supply chain system to improve the sustainability index profile. Although the overall sustainability of the system is not significantly improved, the proposed model provides an alternative strategy for biodiesel refineries to integrate multiple oil crops as feed without major modification of the process to create a more well-balanced sustainability index profile. This current work is best suited to be used as a reference for biodiesel stakeholders to improve the existing sustainability issue. For instance, the model improved an overly poor sustainably index system (Figure 5) to a more well-rounded sustainability profile in Figure 7. The decision to integrate multiple oil crops as biodiesel refinery feed can be made based on the level of sustainability improvement and the associated cost increment. Nonetheless, the improvement of the system is still subjected to the sustainability index profile of the existing oil crops. The system may not be able to improve the sustainability problem significantly if most of the oil crops considered in the study have a relatively low sustainability index profile. Implementation of the comparative sustainability index in this work provides an excellent platform to identify such bottlenecks in the biodiesel industry. For example, the case studies have demonstrated that even at the highest sustainability level, sustainability aspects such as water impact, fertiliser impact and oil yield are still achieved a relatively low score as shown in Figures 6 and 7. This information can be used by researchers or companies to strategise the development effort and direction. 


\section{Conclusions}

The proposed model has shown its potential to reduce production costs and improve sustainability profiles by integrating multiple oil crops based on their properties. The restriction of the conventional biodiesel supply chain network limits single species of oil crops to be used in each refinery, which subsequently creates an overly poor or good feed sustainability profile. Case studies presented in this paper had shown that the integration of multiple oil crops could generate a lower production cost and a more balanced sustainability profile for the system. However, the balanced sustainability profile can only be achieved at the expense of higher production costs. Therefore, it is recommended that the proposed approach to integrate multiple oil crops is used as a temporary solution to improve the overall sustainability profile of biodiesel production. This will not be the ultimate solution for the industry as the development of new methods and technology are still required to enhance the sustainable practice in each oil crop plantation. Nonetheless, the proposed mathematical optimisation model can be used as a decision-making tool to evaluate the feasibility of multiple oil crops' integration based on the proposed increment in production cost and to determine the bottlenecks of the sustainability aspects of the system via the comparative sustainability index. Apart from that, the current optimisation model can be further improved and modified to study more scenarios in the biodiesel industry. The supply chain network can be evaluated to include more oil crop species and availability, consider the refinery plant capacity limitation and perform detailed production cost calculations. As mentioned as part of the limitation, properties acceptance range can be studied in more detail to determine the actual flexibility of each biodiesel refinery process. In addition, the weightage distribution of sustainability factors for each refinery can be investigated further by considering the regional sustainability policy, incentives, improvement in technology availability and limitations.

Author Contributions: Conceptualisation, C.H.L., W.X.C. and Y.W.P.; methodology, C.H.L., W.X.C. and Y.W.P.; software, C.H.L. and W.X.C.; writing-original draft preparation, C.H.L.; writing-review and editing, B.S.H., W.P.Q.N., S.Y.T., W.D.L., S.L.N. and H.L.L.; visualisation, C.H.L.; supervision, C.H.L.; funding acquisition, C.H.L., S.Y.T., B.S.H. and S.L.N. All authors have read and agreed to the published version of the manuscript.

Funding: This research was funded by Universiti Tunku Abdul Rahman Research Fund, grant number IPSR/RMC/UTARRF/2018-C2/L05. The research contribution from S.Y. Teng has also received funding from the Ministry of Education, Youth and Sports, Czech Republic under OP RDE grant number CZ.02.1.01/0.0/0.0/16_026/0008413 "Strategic Partnership for Environmental Technologies and Energy Production"; B.S. How would like to acknowledge the financial support from Swinburne University of Technology Sarawak Campus via Research Supervision Grant, grant number 2-5545 RSG and S.L. Ngan would like to acknowledge the financial support by the MPOB-UKM Endowment Chair: Small Grant Program [EP-2020-027].

Conflicts of Interest: The authors declare no conflict of interest.

\section{Nomenclature}

$\begin{array}{ll}\text { Sets/subscripts } & \text { Description } \\ s & \text { Sustainability aspects } \\ f & \text { Oil crops resources } \\ p & \text { Oil crops' properties } \\ r & \text { Biodiesel refinery } \\ m & \text { Biodiesel market } \\ \text { Variables } & \text { Description } \\ \text { Oil } & \text { Transported oil crop amount }\left(\mathrm{t} \cdot \mathrm{y}^{-1}\right) \text { from resource point, } f \text {, to refinery, } r \\ F_{r} & \text { Total oil crop }\left(\mathrm{t} \cdot \mathrm{y}^{-1}\right) \text { received at each refinery, } f \\ D_{r} & \text { Total biodiesel produced }\left(\mathrm{t} \cdot \mathrm{y}^{-1}\right) \text { at each refinery, } f \\ \text { Biodiesel }_{r, m} & \text { Transported biodiesel amount }\left(\mathrm{t} \cdot \mathrm{y}^{-1}\right) \text { from refinery, } r, \mathrm{to} \text { market, } m \\ \text { Oil_Cost } & \text { Total cost of oil crops used in the system }\left(\mathrm{USD} \cdot \mathrm{y}^{-1}\right) \\ \text { Pro_Cost } & \text { Total production cost of biodiesel in the system }\left(\mathrm{USD} \cdot \mathrm{y}^{-1}\right) \\ \text { Log_Cost }_{\text {Cog }} \text { ) } & \text { Total transportation cost in the system }\left(\mathrm{USD} \cdot \mathrm{y}^{-1}\right) \\ \text { Total_Cost } & \text { Overall cost in the system to fulfil the biodiesel demand }\left(\mathrm{USD} \cdot \mathrm{y}^{-1}\right)\end{array}$




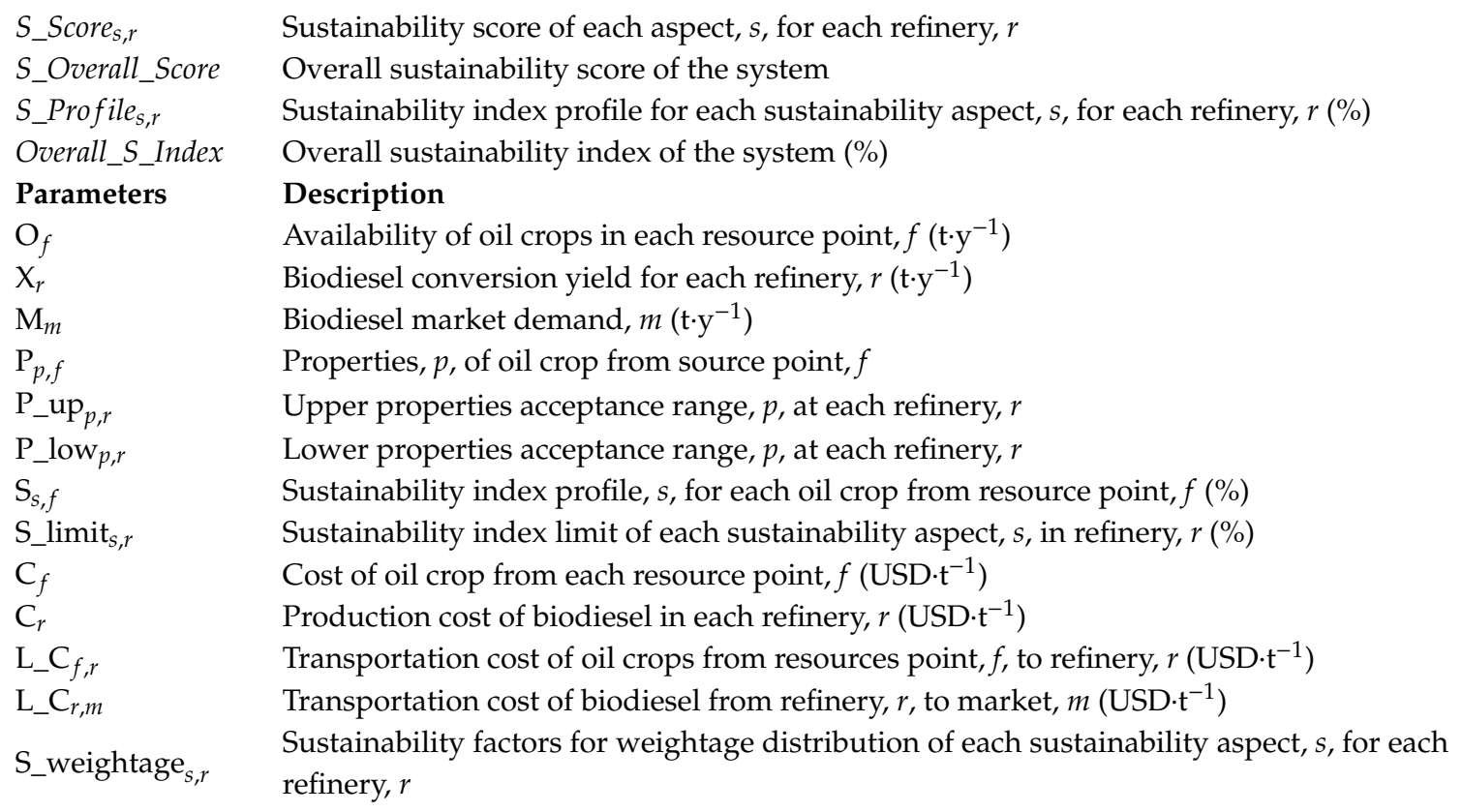

\section{References}

1. Lotero, E.; Liu, Y.; Lopez, D.E.; Suwannakarn, K.; Bruce, D.A.; Goodwin, J.G. Synthesis of biodiesel via acid catalysis. Ind. Eng. Chem. Res. 2005, 44, 5353-5363. [CrossRef]

2. Al-Hamamre, Z.; Yamin, J. Parametric study of the alkali catalyzed transesterification of waste frying oil for Biodiesel production. Energy Convers. Manag. 2014, 79, 246-254. [CrossRef]

3. Drapcho, C.M.; Nhuan, N.P.; Walker, T.H. Biofuels Engineering Process Technology; Mc Graw Hill: New York, NY, USA, 2008.

4. Tatikonda, N.C.; Naveenchandran, P. The behaviour of a compression ignition engine under the influence of diesel and microalgae biodiesel blends. Int. J. Mech. Prod. Eng. Res. Dev. 2019, 9, 447-456. [CrossRef]

5. Sharma, P.K.; Saharia, M.; Srivstava, R.; Kumar, S.; Sahoo, L. Tailoring microalgae for efficient biofuel production. Front. Mar. Sci. 2018, 5, 382. [CrossRef]

6. Khatun, R.; Reza, M.I.H.; Moniruzzaman, M.; Yaakob, Z. Sustainable oil palm industry: The possibilities. Renew. Sustain. Energy Rev. 2017, 76, 608-619. [CrossRef]

7. Foong, S.Z.Y.; Goh, C.K.M.; Supramaniam, C.V.; Ng, D.K.S. Input-output optimisation model for sustainable oil palm plantation development. Sustain. Prod. Consum. 2019, 17, 31-46. [CrossRef]

8. Hombach, L.E.; Büsing, C.; Walther, G. Robust and sustainable supply chains under market uncertainties and different risk attitudes-A case study of the German biodiesel market. Eur. J. Oper. Res. 2018, 269, 302-312. [CrossRef]

9. Habib, M.S.; Asghar, O.; Hussain, A.; Imran, M.; Mughal, M.P.; Sarkar, B. A robust possibilistic programming approach toward animal fat-based biodiesel supply chain network design under uncertain environment. J. Clean. Prod. 2020, 278, 122403. [CrossRef]

10. Mohseni, S.; Pishvaee, M.S. Data-driven robust optimization for wastewater sludge-to-biodiesel supply chain design. Comput. Ind. Eng. 2020, 139, 105944. [CrossRef]

11. Ghelichi, Z.; Saidi-mehrabad, M.; Pishvaee, M.S. A stochastic programming approach toward optimal design and planning of an integrated green biodiesel supply chain network under uncertainty: A case study. Energy 2018, 156, 661-687. [CrossRef]

12. He, Y.; Zhang, B.; Guo, S.; Guo, Z.; Chen, B.; Wang, M. Sustainable biodiesel production from the green microalgae Nannochloropsis: Novel integrated processes from cultivation to enzyme-assisted extraction and ethanolysis of lipids. Energy Convers. Manag. 2020, 209, 112618. [CrossRef]

13. Mahmood Khan, H.; Iqbal, T.; Haider Ali, C.; Javaid, A.; Iqbal Cheema, I. Sustainable biodiesel production from waste cooking oil utilizing waste ostrich (Struthio camelus) bones derived heterogeneous catalyst. Fuel 2020, 277, 118091. [CrossRef] 
14. De Mora, E.F.; Torres, C.; Valero, A. Thermoeconomic analysis of biodiesel production from used cooking oils. Sustainability 2015, 7, 6321-6335. [CrossRef]

15. Zheng, T.; Wang, B.; Rajaeifar, M.A.; Heidrich, O.; Zheng, J.; Liang, Y.; Zhang, H. How government policies can make waste cooking oil-to-biodiesel supply chains more efficient and sustainable. J. Clean. Prod. 2020, 263, 121494. [CrossRef]

16. Gozmen Şanli, B.; Uludamar, E.; Özcanli, M. Evaluation of energetic-exergetic and sustainability parameters of biodiesel fuels produced from palm oil and opium poppy oil as alternative fuels in diesel engines. Fuel 2019, 258. [CrossRef]

17. Lim, C.H.; Chuen, W.W.Z.; Foo, J.Q.; Tan, T.J.; How, B.S.; Ng, W.P.Q.; Lam, H.L. Circular sustainability optimisation model for diverse oil crops feedstock system via element targeting approach. Chem. Eng. Trans. 2019, 76, 1111-1116. [CrossRef]

18. Sitepu, E.K.; Heimann, K.; Raston, C.L.; Zhang, W. Critical evaluation of process parameters for direct biodiesel production from diverse feedstock. Renew. Sustain. Energy Rev. 2020, 123, 109762. [CrossRef]

19. Dos Santos Alves, C.E.; Belarmino, L.C.; Padula, A.D. Feedstock diversification for biodiesel production in Brazil: Using the Policy Analysis Matrix (PAM) to evaluate the impact of the PNPB and the economic competitiveness of alternative oilseeds. Energy Policy 2017, 109, 297-309. [CrossRef]

20. Lim, C.H.; Lam, H.L. Biomass supply chain optimisation via novel Biomass Element Life Cycle Analysis (BELCA). Appl. Energy 2016, 161, 733-745. [CrossRef]

21. Janbarari, S.R.; Ahmadian Behrooz, H. Optimal and robust synthesis of the biodiesel production process using waste cooking oil from different feedstocks. Energy 2020, 198, 117251. [CrossRef]

22. Singh, D.; Sharma, D.; Soni, S.L.; Sharma, S.; Kumar Sharma, P.; Jhalani, A. A review on feedstocks, production processes, and yield for different generations of biodiesel. Fuel 2020, 262, 116553. [CrossRef]

23. Ghiasy-Oskoee, M.; Hatterman-Valenti, H.; Monono, E.; AghaAlikhani, M. Blessed thistle a promising species on North Dakota, USA marginal lands: Agronomic productivity, oil properties and biodiesel potential. Ecol. Eng. 2020, 155, 105908. [CrossRef]

24. European Commision. The Impact of EU Consumption on Deforestation: Comprehensive Analysis of the Impact of EU Consumption on Deforestation; European Union: Brussels, Belgium, 2013.

25. Kurki, A.; Hill, A.; Morris, M. Biodiesel: The Sustainability Dimensions. Available online: https://attra.ncat. org/attra-pub/download.php?id=312 (accessed on 17 July 2020).

26. Mekonnen, M.M.; Hoekstra, A.Y. The green, blue and grey water footprint of crops and derived crop products. Hydrol. Earth Syst. Sci. 2011, 15, 1577-1600. [CrossRef]

27. Saswattecha, K.; Kroeze, C.; Jawjit, W.; Hein, L. Assessing the environmental impact of palm oil produced in Thailand. J. Clean. Prod. 2015, 100, 150-169. [CrossRef]

28. Forleo, M.B.; Palmieri, N.; Suardi, A.; Coaloa, D.; Pari, L. The eco-efficiency of rapeseed and sunflower cultivation in Italy. Joining environmental and economic assessment. J. Clean. Prod. 2018, 172, 3138-3153. [CrossRef]

29. Lima, M.; Skutsch, M.; Costa, G.D.M. Deforestation and the Social Impacts of Soy for Biodiesel: Perspectives of Farmers in the South Brazilian Amazon. Ecol. Soc. 2011, 16, 4. [CrossRef]

30. Zortea, R.B.; Maciel, V.G.; Passuello, A. Sustainability assessment of soybean production in Southern Brazil: A life cycle approach. Sustain. Prod. Consum. 2018, 13, 102-112. [CrossRef]

31. Muñoz, I.; Schmidt, J.H.; Dalgaard, R. Comperative life cycle assessment of five different vegetable oils. In Proceedings of the 9th International Conference on Life Cycle Assessment in the Agri-Food Sector, San Francisco, CA, USA, 8-10 October 2014; pp. 886-894.

32. Alviso, D.; Artana, G.; Duriez, T. Prediction of biodiesel physico-chemical properties from its fatty acid composition using genetic programming. Fuel 2020, 264, 116844. [CrossRef]

33. Macawile, M.C.; Quitain, A.T.; Kida, T.; Tan, R. Green synthesis of sulfonated organosilane functionalized multiwalled carbon nanotubes and its catalytic activity for one-pot conversion of high free fatty acid seed oil to biodiesel. J. Clean. Prod. 2020, 275, 123146. [CrossRef]

34. De Almeida, D.T.; Viana, T.V.; Costa, M.M.; Silva, C.D.S.; Feitosa, S. Effects of different storage conditions on the oxidative stability of crude and refined palm oil, olein and stearin (Elaeis guineensis). Food Sci. Technol. 2019, 39, 211-217. [CrossRef] 
35. Pinzi, S.; Garcia, I.L.; Lopez-Gimenez, F.J.; De Castro, M.D.L.; Dorado, G.; Dorado, M.P. The Ideal Vegetable Oil-based Biodiesel Composition: A Review of Social, Economical and Technical Implications. Energy Fuels 2009, 23, 2325-2341. [CrossRef]

36. Huo, K.; Shui, L.; Mai, Y.; Zhou, N.; Liu, Y.; Zhang, C.; Niu, J. Effects of exogenous abscisic acid on oil content, fatty acid composition, biodiesel properties and lipid components in developing Siberian apricot (Prunus sibirica) seeds. Plant. Physiol. Biochem. 2020, 154, 260-267. [CrossRef] [PubMed]

37. Ma, Y.; Bi, Q.; Li, G.; Liu, X.; Fu, G.; Zhao, Y.; Wang, L. Provenance variations in kernel oil content, fatty acid profile and biodiesel properties of Xanthoceras sorbifolium Bunge in northern China. Ind. Crops Prod. 2020, 151, 112487. [CrossRef]

38. Roiaini, M.; Ardiannie, T.; Norhayati, H. Physicochemical properties of canola oil, olive oil and palm olein blends. Int. Food Res. J. 2015, 22, 1227-1233.

39. Haas, M.J.; McAloon, A.J.; Yee, W.C.; Foglia, T.A. A process model to estimate biodiesel production costs. Bioresour. Technol. 2006, 97, 671-678. [CrossRef]

40. Lam, H.L.; Ng, W.P.Q.; Ng, R.T.L.; Ng, E.H.; Aziz, M.K.A.; Ng, D.K.S. Green strategy for sustainable waste-to-energy supply chain. Energy 2013, 57, 4-16. [CrossRef]

41. Tridge Market Intelligence. Available online: https://www.tridge.com/ (accessed on 15 March 2020).

42. Ward, M.; Kim, G. China-Peoples Republic of Biofuels Annual China Will Miss E10 by 2020 Goal by Wide Margin; USDA Foreign Agricultural Service: Washington, DC, USA, 2019.

43. Emily, C. Malaysia 2019 Biodiesel Output, Exports Seen at Record Highs: Industry Association. Available online: https://www.reuters.com/article/us-malaysia-palmoil-biodiesel/malaysia-2019-biodieseloutput-exports-seen-at-record-highs-industry-association-idUSKCN1UK06R (accessed on 31 July 2020).

44. Thangaraj, B.; Solomon, P.R.; Muniyandi, B.; Ranganathan, S.; Lin, L. Catalysis in biodiesel production-A review. Clean Energy 2019, 3, 2-23. [CrossRef]

45. Chu, Y.; Kung, Y. A study on vegetable oil blends. Food Chem. 1998, 62, 191-195. [CrossRef]

46. Levec, J. Transesterification of canola, palm, peanut, soybean and sunflower oil with methanol, ethanol, isopropanol, butanol and tert-butanol to biodiesel: Modelling of chemical equilibrium, reaction kinetics and mass transfer based on fatty acid composit. Appl. Energy 2014, 123, 108-120. [CrossRef]

(C) 2020 by the authors. Licensee MDPI, Basel, Switzerland. This article is an open access article distributed under the terms and conditions of the Creative Commons Attribution (CC BY) license (http://creativecommons.org/licenses/by/4.0/). 